\section{Effect of Time Lapse on the Diagnostic Accuracy of Cone Beam Computed Tomography for Detection of Vertical Root Fractures}

\author{
Amir Eskandarloo ${ }^{1}$, Amin Mahdavi Asl ${ }^{2}$, Mohsen Jalalzadeh ${ }^{3}$, Maryam Tayari ${ }^{4}$, \\ Mohammad Hosseinipanah ${ }^{5}$, Javad Fardmal ${ }^{6}$, Abbas Shokri ${ }^{1}$
}

\begin{abstract}
Accurate and early diagnosis of vertical root fractures (VRFs) is imperative to prevent extensive bone loss and unnecessary endodontic and prosthodontic treatments. The aim of this study was to assess the effect of time lapse on the diagnostic accuracy of cone beam computed tomography (CBCT) for VRFs in endodontically treated dog's teeth. Fortyeight incisors and premolars of three adult male dogs underwent root canal therapy. The teeth were assigned to two groups: VRFs were artificially induced in the first group $(n=24)$ while the teeth in the second group remained intact $(n=24)$. The CBCT scans were obtained by NewTom $3 \mathrm{G}$ unit immediately after inducing VRFs and after one, two, three, four, eight, 12 and 16 weeks. Three oral and maxillofacial radiologists blinded to the date of radiographs assessed the presence/absence of VRFs on CBCT scans. The sensitivity, specificity and accuracy values were calculated and data were analyzed using SPSS v.16 software and ANOVA. The total accuracy of detection of VRFs immediately after surgery, one, two, three, four, eight, 12 and 16 weeks was $67.3 \%, 68.7 \%, 66.6 \%, 64.6 \%, 64.5 \%$, $69.4 \%, 68.7 \%, 68 \%$ respectively. The effect of time lapse on detection of VRFs was not significant $(p>0.05)$. Overall sensitivity, specificity and accuracy of CBCT for detection of VRFs were $74.3 \%, 62.2 \%, 67.2 \%$ respectively. Cone beam computed tomography is a valuable tool for detection of VRFs. Time lapse (four months) had no effect on detection of VRFs on CBCT scans.
\end{abstract}

\author{
'Dental Research Center, \\ Department of Oral and \\ Maxillofacial Radiology,Dental \\ School, Hamadan University of \\ Medical Sciences, Hamadan,Iran \\ ${ }^{2}$ Department of Oral and \\ Maxillofacial Radiology, Dental \\ School, Golestan University of \\ Medical Sciences, Gorgan, Iran \\ ${ }^{3}$ Department of Endodontics, Dental \\ School, Hamadan University of \\ Medical Sciences, Hamadan, Iran \\ ${ }^{4}$ Department of Pedodontics, Dental \\ School, Golestan University of \\ Medical Sciences, Gorgan, Iran \\ ${ }^{5}$ Department of Anatomy, School of \\ Medicine, Hamadan University of \\ Medical Sciences, Hamadan, Iran \\ ${ }^{6}$ Research Center for Health Sciences \\ and Department of Epidemiology \\ Et Biostatistics, School of Public \\ Health, Hamadan University of \\ Medical Sciences, Hamadan, Iran
}

Correspondence: Abbas Shokri, Shahid Fahmideh Blvd, in front of Mardom Park, 6516647447 Hamadan, 1ran. Tel: +98-381-8251885.

e-mail: Dr.a.shokri@gmail.com

Key Words: cone-beam computed tomography, tooth root, fracture, dogs.

\section{Introduction}

Diagnosis of vertical root fractures (VRFs) is difficult (1) because they may not manifest pathognomonic radiographic or clinical signs and symptoms. Presence of multiple sinus tracts, deep pockets and bone loss in a tooth, lateral 'halo' type radiolucency and swelling and pain during chewing are some of the diagnostic signs and symptoms of VRFs $(2,3)$.

The diagnosis of VRF is only made by direct visualization; therefore exploratory surgery is required to confirm VRFs. After flap elevation, the fracture line is visualized under light and magnification following staining with methylene blue (4). Superposition of the adjacent structures may complicate detection of fracture lines on periapical radiographs $(5,6)$. A VRF may be visible on a periapical radiograph only when the fracture line and $x$-ray beam lie in the same plane or have a $4^{\circ}$ difference at most (7).

The inability of conventional imaging modalities to detect VRFs requires the use of a three-dimensional imaging system $(8,9)$. Cone beam computed tomography (CBCT) is an advanced three-dimensional imaging technique studied for this purpose. However, presence of metal posts and some root canal filling materials may decrease its accuracy
$(5,10)$. Some previous studies compared the accuracy of conventional and digital intraoral radiography and CBCT for detection of VRFs and reported that CBCT and CT were significantly superior for this purpose (6), while some others reported similar accuracy of CBCT and digital radiography. Because of its two-dimensional nature and multiple superpositions, intraoral radiography has many limitations for detecting VRFs. This is especially the case when the fracture line has a mesiodistal orientation; in this condition, the sensitivity decreases to about 7.7\% (5). CBCT provides high quality images; it also eliminates the overlapping of the structures.

Some studies compared CBCT and CT and reported high diagnostic values for both techniques. Nevertheless, CBCT has several advantages over CT including significantly lower patient radiation dose, lower cost, easier access and quick and easy image acquisition (11). Most previous studies on the value of CBCT for detection of VRFs had a crosssectional design and were performed on extracted teeth, and the effect of time lapse on diagnostic accuracy of CBCT for detection of VRFs has not been evaluated. This study sought to assess the effect of time lapse on the diagnostic accuracy of CBCT for detection of VRFs in endodontically treated dog's teeth. 


\section{Material and Methods}

The research protocol was approved by the Ethics Committee of Hamadan University of Medical Sciences with reference number $p / 16 / 35 / 228$. Three adult male dogs were selected and vaccinated according to the guidelines. All three dogs had sound teeth with no fractures, carious lesions or clinical signs of infection. First, CBCT scans were obtained to ensure that the teeth were intact and had no periodontal, periapical or pulpal lesions. Adult dogs have 42 teeth. Sixteen teeth were chosen in each dog including six incisors and two first premolars in each jaw; all of them were single-rooted and single-canal. One canine, two premolars and four molars per quadrant (a total of 26 teeth in each dog) did not undergo any intervention in order to allow normal feeding. Thus, a total of 48 teeth in three dogs received root canal treatment. The teeth were divided into two groups of experimental (for artificial induction of VRF) and control (no intervention). Vertical root fractures were artificially induced in 24 teeth. Twenty-four teeth remained intact (no intervention) and served as controls.

An anesthesiologist induced general anesthesia in dogs followed by intramuscular anesthesia using a combination of $4 \mathrm{mg} / \mathrm{kg}$ body weight ketamine hydrochloride (Calypsol, Medimpex, Hungary) and $0.3 \mathrm{~mL} / \mathrm{kg}$ body weight $3 \%$ pentobarbital solution (Foshan Chemical Engineering Experimental Factory, Foshan, China). Local anesthesia was also induced by injection of $0.02 \%$ lidocaine and the teeth underwent endodontic treatment. The dogs were then positioned on the CBCT scanner bed with their heads in the respective position in the gantry.

The root canal length in each tooth was originally measured on CBCT scans. Following access cavity preparation, the working length was confirmed by periapical radiography (Fig. 1). After selecting the initial file, the filing was continued for a further two or three sizes (Mani Inc., Utsunomiya, Tochigi, Japan); Gates Glidden drills (Mani Inc.) numbers 1, 2 and 3 were also used for coronal preparation. The canals were repeatedly irrigated with freshly prepared $2 \%$ solution of sodium hypochlorite $(\mathrm{NaOCl})$ using a $5 \mathrm{cc}$ syringe and a 27 gauge needle. After completion of the procedure, canals were rinsed with $2 \mathrm{~mL}$ of distilled water. After filling the root canals with guttapercha (Gapadent, Tianjin, China) and AH26 sealer (Dentsply, Konstanz, Germany), the coronal three millimeters of the root canal filling was removed from the canal. Half of the teeth $(n=24)$ remained intact and comprised the control group while in the other half VRFs were artificially induced as described by Monaghanatall et al (12). For this purpose, a sterile conical metal wedge at $60^{\circ}$ bevel was fitted in the emptied canal. Using a hammer, $500 \mathrm{mg}$ load was applied to the end of the wedge by tapping in order to induce a VRF. The presence of fracture was confirmed by observation of intracanal bleeding and then the teeth were sealed using self-cure glass ionomer (Dentsply) and the crowns were shortened by two millimeters; CBCT scans were obtained immediately after inducing the fractures.

The dogs were studied for 16 weeks and during this period they were given soft foods, examined every day to ensure absence of dentoalveolar abscess and their general health was monitored. Subsequently, images were taken at one, two, three, four, eight, 12 and 16 weeks after inducing VRFs. After 16 weeks, the dogs were anesthetized using sodium pentobarbital and euthanized by potassium injection (12). The maxilla and mandible were immediately separated and the fracture lines were inspected under magnification following staining with methylene blue dye.

The CBCT scans were obtained using the New Tom $3 \mathrm{G}$ system (QR SLR, Verona, Italy) at $110 \mathrm{kVp}, 3.2 \mathrm{~mA}, 1.1 \mathrm{~s}$, 6 inches field of view (FOV) and isotropic voxel size of $200 \mu$. The CBCT scans were examined by three oral and maxillofacial radiologists blinded to the date of scans and presence or absence of VRFs. Reconstruction and observation of images were carried out using NNT Viewer software (NewTom, Verona, Italy) and in all three planes, axial, coronal and sagittal (Figs. 2 and 3). The examiners observed the images on a 15-inch liquid crystal display monitor (Toshiba, satellite L40, Japan) with $1367 \times 768$ pixels resolution in a dimly lit room with no time restrictions and determined the presence/absence of VRFs using the following scoring system: 0 indicated no fracture; $1=$ uncertain if fracture is present or

Figure 1. Measuring the length of root canals on the initial CBCT scan. 
not; and 2 = fracture definitely present (16). Images were viewed under standard conditions. Viewing was repeated
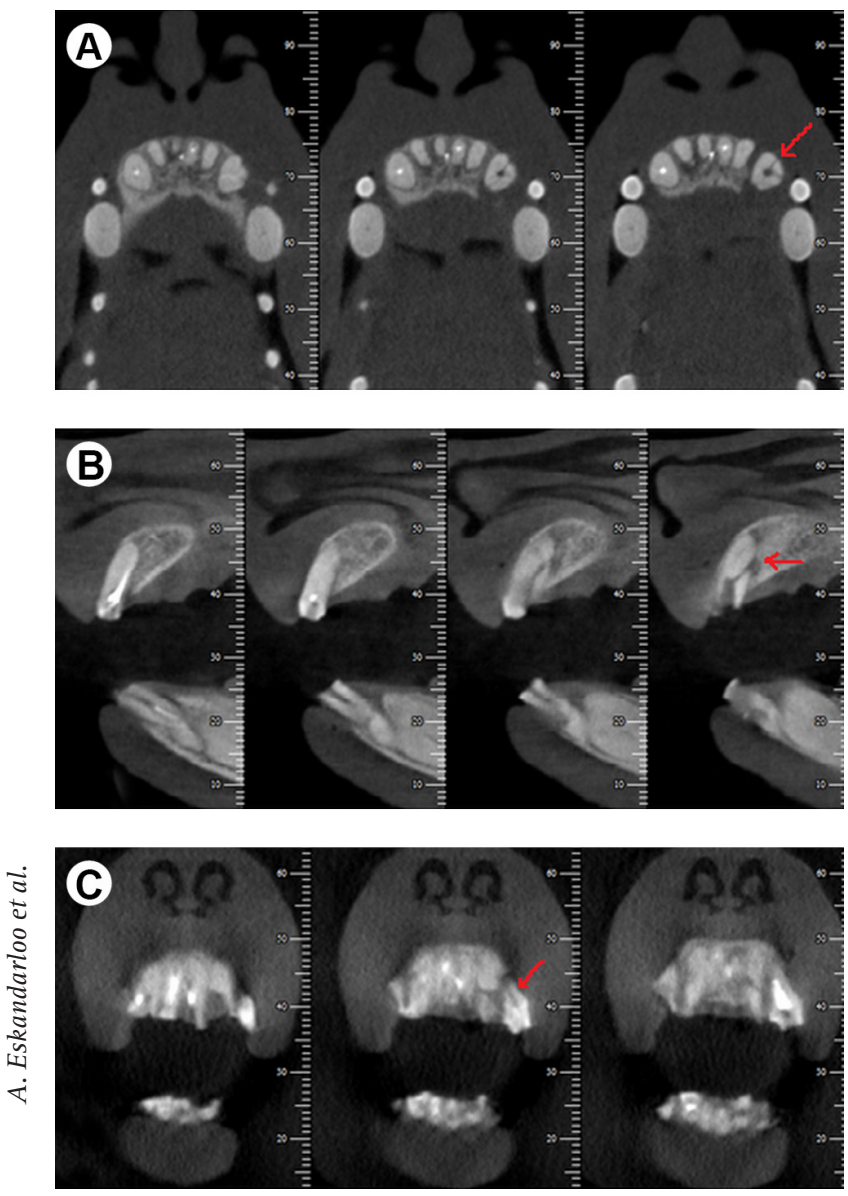

Figure 2. New Tom CBCT image reconstruction. A: Axial view, B: Sagittal view, C: Coronal view. The arrow shows the VRF line. two weeks later to assess intraobserver reliability.

The data were analyzed using SPSS version 16 software (Microsoft, IL, USA). ANOVA was used for comparison of the values at different time points. $p<0.05$ was considered statistically significant. Scores 0 and 1 were considered as absence of fracture and score 2 was considered as presence of fracture in statistical analysis (13). In assessment of sensitivity, specificity and accuracy of CBCT, observing a fracture in one of the planes meant that the tooth had a fracture. Direct visualization of tooth fracture in the mandible or maxilla (separated from the dogs) was considered as the gold standard and the sensitivity, specificity and accuracy values were calculated accordingly. The interobserver agreement was calculated for each plane (axial, coronal and sagittal) using Kappa statistics.

\section{Results}

The values of sensitivity, specificity and accuracy of three observers at different time points are presented in Table 1. Based on the results, sensitivity $(p=0.769)$, specificity $(p=0.236)$ and accuracy $(p=0.985)$ values were not significantly different at the afore-mentioned time points.

Overall sensitivity, specificity and accuracy of CBCT for detection of VRFs were $74.3 \%, 62.2 \%$ and $67.2 \%$ respectively.

Table 2 shows the sensitivity, specificity and positive and negative predictive values for the maxilla and mandible. No significant difference was noted in diagnostic sensitivity for VRFs between the maxilla and mandible ( $p=0.62$ ).

The interobserver agreement was estimated at $k=0.74$, which shows excellent agreement.
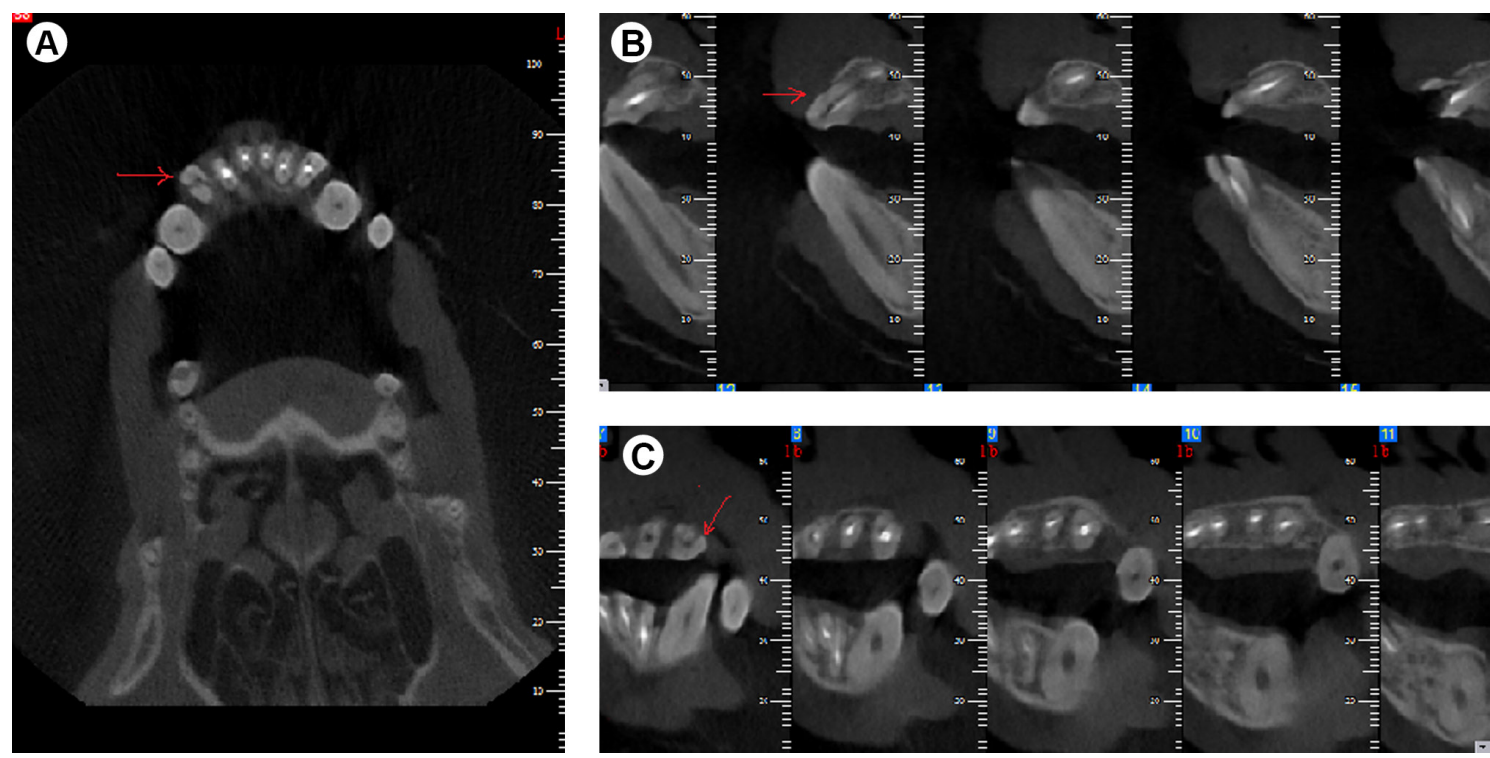

Figure 3. CBCT images. A: Axial view, B: Sagittal view, C: Coronal view. The arrow shows the VRF line. 
Figure 4 shows the interobserver agreement values among the examiners at different time points for detection of VRFs. Intraobserver agreement (Карра) was 0.82.

\section{Discussion}

Numerous ex vivo studies have concluded that CBCT is suitable for detection of VRFs in endodontically treated teeth. However, according to Patel et al, these results should be interpreted with caution since the simulated VRFs in some previous studies have been potentially wide enough to be detected clinically and/or radiographically in a clinical setting (14). In addition, ex vivo studies do not take into account subtle patient movements during CBCT scan acquisition; these movements have a negative effect on the reconstruction algorithms and cause motion artifacts that blur the image (15). Patel et al. explained that $\mathrm{CBCT}$ cannot be recommended for the diagnosis of VRFs. Further clinical studies are required to quantify and assess the value of CBCT in diagnosing root fractures, especially in endodontically treated teeth and with a proper control group. However, CBCT may reveal subtle signs of periradicular bone loss associated with an undetected VRF (14). For these reasons, in the current study, VRFs were artificially created to simulate in vivo conditions.

It was found that the overall sensitivity, specificity and accuracy of NewTom 3G CBCT unit for detection of VRFs were $74.3 \%, 62.1 \%$ and $67.2 \%$, respectively.

A clinical study by Youssefzadeh et al. (6) compared conventional radiography with CT and concluded that the sensitivity of CT for detecting fractures was 75\%, while the sensitivity of intraoral radiography was $25 \%$. Because of its two-dimensional nature and multiple superpositions, conventional radiography has many

Table 1. Sensitivity, specificity and accuracy of VRFs at different time points

\begin{tabular}{lccc}
\hline Time & Sensitivity $(\%)$ & Specificity $(\%)$ & Accuracy $(\%)$ \\
\hline $\begin{array}{l}\text { Immediately } \\
\text { after surgery }\end{array}$ & 65 & 68.8 & 67.3 \\
One week & 75 & 64.2 & 68.7 \\
Two weeks & 76.6 & 59.4 & 66.6 \\
Three weeks & 71.6 & 59.5 & 64.6 \\
Four weeks & 85 & 50 & 64.5 \\
Two months & 73.3 & 66.6 & 69.4 \\
Three months & 70 & 67.9 & 68.7 \\
Four months & 78.3 & 60.7 & 68 \\
Total & 74.3 & 62.2 & 67.2 \\
p-value & 0.769 & 0.236 & 0.985 \\
\hline
\end{tabular}

limitations for detecting VRFs. This is especially the case when the fracture line has a mesiodistal orientation; in this condition, the sensitivity decreases to about 7.7\% (5). Because of its three-dimensional nature and the ability to prevent superimpositions, СBCT has a high potential for detection of VRFs. The accuracy of CBCT for detection of VRFs also appears to be dependent on the CBCT device used. Several studies have assessed different CBCT scanners and found varying degrees of diagnostic accuracy for detecting simulated VRFs (16). The quality of CBCT scans, their contrast and resolution depend on the detector type, size of FOV, voxel size, artifact level and the amount of basic images and algorithm of scan reconstruction (16). The difference between the sensitivity of CBCT device obtained in the present study and that of previous studies may be due to the type of detector, detector sensitivity, exposure parameters, voxel settings and reconstruction algorithms of the assessed CBCT scanners (16).

It does appear that CBCT accuracy is associated with voxel size; the smaller the voxel size the more reliable the interpretation (18). Some CBCT scanners allow the users to choose between high and low resolution modes while scanning a patient. High-resolution mode has a smaller voxel size and results in higher spatial resolution of scanning and consequently higher accuracy for detection of root complications but the patient radiation dose is higher in this mode (19).

Metal artifacts related to radiopaque materials inside the canal decrease the accuracy of CBCT in detecting

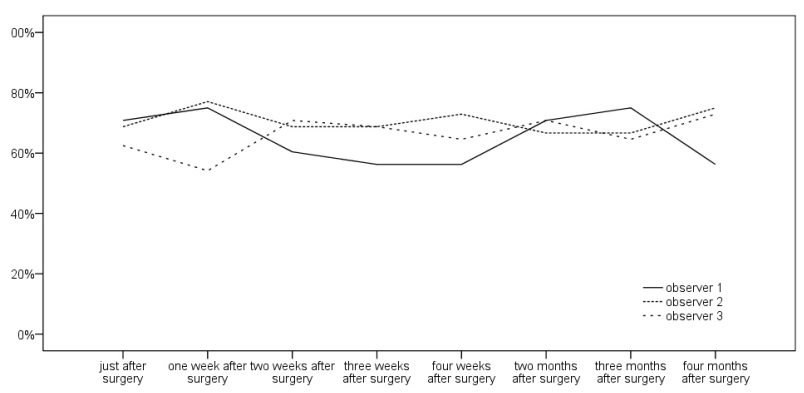

Figure 4. Interobserver agreement values among the examiners at different time points for detection of VRFs.

Table 2. Sensitivity, specificity, false positive and false negative of VRFs at different jaws

\begin{tabular}{lcccc}
\hline Jaw & $\begin{array}{c}\text { Sensitivity } \\
(\%)\end{array}$ & $\begin{array}{c}\text { Specificity } \\
(\%)\end{array}$ & $\begin{array}{c}\text { False } \\
\text { positive (\%) }\end{array}$ & $\begin{array}{c}\text { False } \\
\text { negative (\%) }\end{array}$ \\
\hline Maxilla & 78.3 & 55 & 21.7 & 45 \\
Mandible & 68.1 & 78.6 & 31.9 & 21.4 \\
Total & 73.8 & 67.7 & 26.2 & 32.3 \\
\hline
\end{tabular}


endodontic complications (10). According to Hassan et al, (5) streak artifacts associated with root canal filling could mimic fracture and reduce the specificity of CBCT scans in diagnosis.

Salineiro et al. (20) analyzed four different CBCT protocols to identify horizontal root fractures in endodontically treated teeth, with or without a metallic post. The sensitivity, specificity and accuracy values were better for the $8^{*} 8 \mathrm{~cm} / 0.2 \mathrm{~mm}$ and $16^{*} 6 \mathrm{~cm} / 0.25 \mathrm{~mm}$ protocols, ranging from 0.60 to 0.86 and 0.53 to 0.80 , respectively. The $8^{*} 8 \mathrm{~cm} / 0.2 \mathrm{~mm}$ protocol had the least interference from the metallic artifact.

Metska et al. (21) studied the capability of detecting VRFs by NewTom $3 \mathrm{G} \mathrm{CBCT}$ in humans. The total accuracy of the system was $68 \%$. These results are close to the findings of the current study, where the accuracy was found to be $67.2 \%$. In a study by Metska et al., CBCT scans were obtained just once, and although the patients were under follow-up until surgery or extraction, further CBCT imaging was not performed. Therefore, the influence of time on improving the accuracy of radiographic diagnosis of VRFs was not analyzed. (21).

Spatial resolution is the ability of an imaging system to distinguish small structures that lie close to one another. It is an important parameter because it is directly linked to diagnostic efficacy. The CBCT units, in general, provide voxel resolution that is isotropic (equal in three orthogonal planes: axial, coronal and sagittal) (22).

Vertical root fractures allow transportation of bacteria and associated irritations, which cause localized periodontal destruction and bone loss adjacent to the fracture site. The amount of bone loss is dependent on the nature of the fracture and the time since the fracture. The radiographic image of bone loss is dependent on the extent of destruction, the plane of fracture and the architecture of the bone adjacent to the fracture (4).

In the current study, time lapse had no effect on detection of VRFs and the diagnostic accuracy did not improve during the 16-week follow-up period. Therefore, radiographic signs of VRFs may take longer to appear. Also, due to ethical considerations, after inducing the VRFs, the teeth were shortened. Perhaps reducing the pressure of occlusion compensated for the effect of time lapse.

Moreover, in this study, it was assured that the fractures were complete in the first place and not much change occurred over time. However, in previous studies $(6,10)$, most fractures were incomplete and it is possible that the fracture lines propagated further into a complete fracture and became radiographically visible and detectable. Many of the previous studies on VRFs had a cross-sectional design and could not assess the effect of time lapse on diagnostic accuracy of CBCT for VRF detection $(6,10)$.
Makeeva et al. (23) compared the diagnostic accuracy of CBCT for detection of artificially induced VRFs of different widths in vitro and in vivo and concluded that the detectability of VRFs by CBCT in vitro and in vivo depended upon the fracture width. The accuracy of $\mathrm{CBCT}$ in detecting VRFs with 50-300 $\mu \mathrm{m}$ width in vivo was significantly lower compared to the value in vitro. In most previous studies $(23,24)$, the diagnostic accuracy of CBCT for detection of VRFs in vivo has been lower than the value in vitro.

In another clinical study carried out by Wang et al (25) 398 teeth of patients suspected for VRF underwent CBCT, followed by surgery or extraction. Direct observation of VRF was considered as the gold standard. They used 3D Accuitomo CBCT system (J. Morita, Tokyo, Japan) and the sensitivity value was found to be $39 \%$. The sensitivity value in their study was lower than the value in some other studies (6) because the statistical analysis for fracture detection accuracy was different. In the current study and some other similar studies, observing a fracture line in one of the three planes meant that the tooth had a fracture, but in the study by Wang et al (25), the line of fracture had to be observed at least in two planes and this caused a decline in the sensitivity value in their study. In many studies $(6,25)$, the diagnostic accuracy of CBCT has been compared with that of conventional and digital intraoral radiography for detection of VRFs and in all of them CT was found to be superior. In conclusion, overall accuracy of CBCT for detection of VRFs was $67.2 \%$ and CBCT is a valuable tool for detection of VRFs. Time lapse (four months) after artificial induction of VRFs had no effect on the diagnostic accuracy of CBCT.

\section{Resumo}

Um diagnostico correto e a tempo das fraturas radiculares verticais (FRVs) é essencial para prevenir extensa perda óssea, tratamentos endodônticos e próteses desnecessárias. 0 objetivo do presente estudo foi avaliar 0 efeito do tempo decorrido sobre a acurácia diagnóstica da tomografia computadorizada de feixe cônico (TCFC) para detecção de FRVs em dentes de cães tratados endodonticamente. Quarenta e oito dentes incisivos e premolares obtidos de três cães machos adultos tiveram os seus canais tratados. Os dentes foram divididos em dois grupos: no primeiro grupo $(n=24)$ foram artificialmente induzidas FRVs, enquanto no segundo grupo $(n=24)$ os dentes permaneceram intactos. As imagens de TCFC foram obtidas pela unidade NewTom $3 \mathrm{G}$ imediatamente após a cirurgia de indução das FRVs e uma, duas, três, quarto, oito, 12 e 16 semanas depois. Três radiologistas cegos para as datas das imagens avaliaram a presença/ ausência de FRVs nas imagens de TCFC. Foram calculados os valores da sensibilidade, especificidade e acurácia, sendo os dados analisados por ANOVA e pelo programa SPSS v.16. As acurácias totais de detecção das FRVs imediatamente após sua indução e uma, duas, três, quarto, oito, 12 e 16 semanas depois foram respectivamente de 67,3\%,68,7\%,66,6\%, $64,6 \%, 64,5 \%, 69,4 \%, 68,7 \%$ e $68 \%$. 0 efeito do tempo decorrido foi sem significado estatístico $(p>0,05)$. A TCFC produziu valores gerais de sensibilidade, especificidade e acurácia de $74,3 \%, 62,2 \%$ e $67.2 \%$, respectivamente. A tomografia computadorizada de feixe cônico é uma ferramenta valiosa para detecção de FRVs. 0 tempo decorrido (quatro meses) não teve influência sobre a detecção de FRVs nas imagens de TCFC. 


\section{References}

1. Tsesis I, Rosen E, Tamse A, Taschieri S, Kfir A. Diagnosis of vertical root fractures in endodontically treated teeth based on clinical and radiographic indices: a systematic review. J Endod 2010;36:1455-1458.

2. Tamse A, Fuss Z, Lustig J, Kaplavi J. An evaluation of endodontically treated vertically fractured teeth. J Endod 1999;25:506-508.

3. Tamse A, Fuss Z, Lustig J, Ganor Y, Kaffe I. Radiographic features of vertically fractured, endodontically treated maxillary premolars. Oral Surg Oral Med Oral Pathol Oral Radiol Endod 1999;88:348-352.

4. Cohen S, Blanco L, Berman L. Vertical root fractures: clinical and radiographic diagnosis. J Am Dent Assoc 2003;134:434-441.

5. Hassan $B$, Metska ME, Ozok AR, van der Stelt P, Wesselink PR. Detection of vertical root fractures in endodontically treated teeth by a cone beam computed tomography scan. J Endod 2009;35:719-722.

6. Youssefzadeh S, Gahleitner A, Dorffner R, Bernhart T, Kainberger FM. Dental vertical root fractures: value of CT in detection. Radiology 1999;210:545-549.

7. Rud J, Omnell KA. Root fractures due to corrosion. Scand J Dent Res 1970;78:397-403.

8. Nair MK, Nair UDP, Gröndahl HG, Webber RL, Wallace JA. Detection of artificially induced vertical radicular fractures using tuned aperture computed tomography. Eur J Oral Sci 2001;109:375-379.

9. Hannig C, Dullin C, Hulsmann M, Heidrich G. Three-dimensional, nondestructive visualization of vertical root fractures using flat panel volume detector computer tomography: an ex vivo in vitro case report. Int Endod J 2005;38:904-913.

10. D'Addazio P, Campos C, Özcan M, Teixeira H, Passoni R, Carvalho A. A comparative study between cone beam computed tomography and periapical radiographs in diagnosis of simulated endodontic complications. Int Endod J 2011;4:218-224.

11. Shah N, Bansal N, Logani A. Recent advances in imaging technologies in dentistry. World J Radiol 2014;28:794-807.

12. Monaghan P, Bajalcaliev JG, Kaminski EJ, Lautenschlager EP. A method for producing experimental simple vertical root fractures in dog teeth. J Endod 1993;19:512-515.

13. Edlund M, Nair MK, Nair UP. Detection of vertical root fractures by using cone-beam computed tomography: a clinical study. J Endod. 2011;37:768-772.

14. Patel S, Durack C, Abella F, Shemesh H, Roig M, Lemberg K. Cone beam computed tomography in Endodontics - a review. Int Endod J 2015:48:3-15

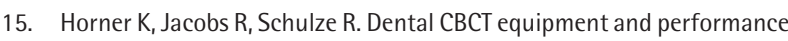
issues. Radiation Protection Dosimetry 2013;153:212-218.

16. Hassan $B$, Metska ME, Ozok AR, van der Stelt $P$, Wesselink PR. Comparison of five cone beam computed tomography systems for the detection of vertical root fractures. J Endod. 2010;36:126-129.

18. Wenzel A, Neto-Haiter F, Frydenberg M, Kirkevang L-L .Variableresolution cone-beam computerized tomography with enhancement filtration compared with intraoral photostimulable phosphor radiography in detection of transverse root fractures in an in vitro model. Oral Surg Oral Med Oral Pathol Oral Radiol Endod 2009; 108:939-945

19. Cheng J-G, Zhang Z-L, Wang X-Y, Zhang Z-Y, Ma X-C, Li G. Detection accuracy of proximal caries by phosphor plate and cone-beam computerized tomography images scanned with different resolutions. Clinical Oral Investigations 2012;16:1015-1021.

20. Salineiro FC, Pinheiro LR, dos Santos Júnior O, Cavalcanti MG. Detection of horizontal root fracture using four different protocols of cone-beam computed tomography. Braz Oral Res 2015. Epub ahead of print. DOI: 10.1590/1807-3107BOR-2015.

21. Metska ME, Aartman IH, Wesselink PR, Ozok AR. Detection of vertical root fractures in vivo in endodontically treated teeth by cone-beam computed tomography scans. J Endod 2012;38:1344-1347.

22. Hodez C, Griffaton-Taillandier C, Bensimon I. Cone beam imaging: Applications in ENT. Eur Ann Otorhinolaryngol Head Neck Dis 2011;128:65-78.

23. Makeeva IM, Byakova SF, Novozhilova NE, Adzhieva EK, Golubeva $\mathrm{Gl}$, Grachev VI, et al.. Detection of artificially induced vertical root fractures of different widths by cone beam computed tomography in vitro and in vivo. Int Endod J 2015. Epub ahead of print. DOI: 10.1111/ iej.12549.

24. Corbella S, Del Fabbro M, Tamse A, Rosen E, Tsesis I, Taschieri S. Cone beam computed tomography for the diagnosis of vertical root fractures: a systematic review of the literature and meta-analysis. Oral Surg Oral Med Oral Pathol Oral Radiol 2014;118:593-602.

25. Wang $P$, Yan XB, Liu DG, Zhang WL, Zhang ZY, Ma XC. Evaluation of dental root fracture using cone-beam computed tomography. Chin J Dent Res 2010;13:31-35. 